\title{
Experimental methods for obtaining fracture data from small specimens
}

\author{
J.P. Dear
}

Imperial College of Science, Technology and Medicine, Department of Mechanical Engineering, Exhibition Road, London SW7 2BX, U.K.

\begin{abstract}
Resumé: Cette publication examine d'abord les problèmes liés à l'utilisation des méthodes d'impact pour obtenir la rupture rapide des polymères. Des juages placées sur l'échantillon sont utilisées pour obtenir la distribution des contraintes de types transitoire et autres en differénts points de l'échantillon. Une nouvelle méthode qui permet d'éviter les efforts transitoires et d'atteindre des vitesses de propagation des fissures dans les petits échantillons de polymères de plus de $300 \mathrm{~m} \mathrm{~s}^{-1}$ est ensuite preséntée. La change nécessaire à juste assurer la propagation d'une fissure peut-ètre mesurée par cette méthode et la vitesse limite des fissures determinée. Un aspect important de cette nouvelle méthode est que la tension dans le matériau peut ètre relaxée graduellement avant d'amorcer la rupture pour la simulation de ces conditions de travail.
\end{abstract}

\begin{abstract}
This paper first examines the problems of using impact methods to achieve fast fracture of polymers. On-specimen gauges are employed to obtain the distribution of transient and other stresses in different parts of the specimen. A new method is then introduced that avoids transient forces and achieves crack velocities in small specimens of tough polymers of over $300 \mathrm{~m} \mathrm{~s}^{-1}$. It provides for the measurement of load to just sustain a running crack and for determining the limiting crack velocity. An important point about the new method is that the material can be allowed to stress relax to various degrees before launching a crack to simulate these different working conditions.
\end{abstract}

\section{INTRODUCTION}

When researching the fracture properties of new materials and comparing them with existing ones, experimental methods used need to have regard for the strain-rate sensitivity and other relevant characteristics of the material and how these affect the applications for which the materials are intended. Other factors to be considered are how the fracture properties of the material are affected by different product geometry, the effect of manufacturing processes, ageing and other life deterioration. A variety of experimental methods are needed to cover all these requirements ranging from those which can realistically evaluate small specimens through to those which are capable of full-scale end product evaluation. It helps if the results from the different fracture evaluation methods used are easily related to each other.

Polymers are interesting materials to study as they have varying degrees of viscoelasticity and other factors affecting their strain-rate sensitivity. They also have a complex microstructure of crystalline and amorphous regions. A result is that polymers have involved fracture processes as indicated by the complexity of their fracture surfaces. When evaluating the fracture toughness of polymers, it is important to note that the value of fracture toughness obtained can vary with the different methods of loading of the specimens. Two fracture methods have been used for the research reported on in this 
paper which illustrates this point. Both only require small specimens and their results can be related to full-scale fracture evaluation of a range of products studied.

Widely used is the Charpy method [1-5] when a small bar specimen is subjected to a rapid three-point bend by an impacting striker. Depending upon the size of the specimen and the velocity of the impacting striker, the fracture conditions can vary greatly. Both the material's resistance to crack initiation and crack propagation affect the results obtained. For polymers, crack initiation resistance varies considerably. However, it is possible by varying the Charpy loading conditions and specimen geometry to assess the initiation and propagation components of the toughness measurements [6]. A factor that cannot be covered by the Charpy method is that in a pressurised pipe and in other applications when the material is subjected to a steady load for long periods, then by creep processes, it reaches a stress relaxed state. A different evaluation method is needed to determine the toughness of polymers when they are in a stress relaxed state and also for studying long cracks in material specimens. For example, pipe manufacturerers are particularly interested in materials that have a high resistance to continuous rapid crack propagation (RCP) when they are loaded and in a stress relaxed state.

This paper examines fracture data obtained from rapid three-point bending of bar specimens using a servo-hydraulic loading machine. Also, a new method is used to obtain fracture data from specimens of a different shape and longer crack path after they have been loaded and allowed to stress relax.

\section{EXPERIMENTAL}

\subsection{Three-point bend method}

There are a variety of special purpose Charpy machines for evaluating standard size bar specimens of material. For this study of polyethylene material, specimens of dimensions $200 \mathrm{~mm} \times 40 \mathrm{~mm} \times 25 \mathrm{~mm}$ were used which were easier to instrument to monitor the variation of strain at the crack tip as it propagated. Specimens of this size were also more suitable for use in a precision high-rate servo-hydraulic machine. The striker was instrumented to monitor the impact forces arising from the interaction between striker and specimen. Figure 1(a) shows the general arrangement and position of both sensors on the specimen and striker. For the force time traces shown, both sensors were $20 \mathrm{~mm}$ from the crack path. This is with the sensors on the specimen measuring strain normal to the crack path. Figure 1 also shows the outputs from the specimen and striker sensors for two different impact velocities of the striker together with photographs of the fracture surfaces. Notable, at the lower impact velocity of $0.5 \mathrm{~m} \mathrm{~s}^{-1}$, are that the saw-tooth outputs from the sensors on the specimen and striker were free of transient ringing (Figure 1(b)). For some tougher materials higher impact velocities are needed and then strong transients can occur on all three sensor outputs and this to different degrees. This is illustrated by the results shown for a $1.1 \mathrm{~m} \mathrm{~s}^{-1}$ impact velocity (Figure 1(c)). These strong transients question the validity of the results obtained. Also, the fracture surfaces for the two different impact striker velocities show variations in the size and surface texture of both the crack initiation and crack propagation zones. In both cases well in evidence are the partial arrest lines and the concluding hinge bend zone. For some of the repeated experiments at the higher impact velocity, the hinge bend zone did not completely fracture and this affected the residual kinetic energy carried away by the specimen as it was driven out of the fixture and this complicated the fracture calculations.

\subsection{Tongue method}

The same polyethylene material was used for these experiments as for the three-point bend ones reported on above. In this case, the specimen's shape and size is different as shown in Figure 2(a). The main section of the specimen was loaded using an Instron machine and then the material was allowed to stress relax. A crack was initiated in the protruding tongue which was an extension of the intended crack path. This was a simple matter for polyethylene specimens as the material is a good thermal insulator so the tongue could be frozen using liquid nitrogen and fractured with a shallow three-point bend tool. It was verified that the cooling of the tongue only affected a small region into the main section less than $10 \mathrm{~mm}$ radius. Also, the presence of the tongue only affected the stress distribution of the main section of the specimen for a few mms. At a distance of $5 \mathrm{~mm}$ from the crack 
path, gauges SG1 and SG2 monitored the strain normal to the crack path as shown in Figure 2(b). The output traces show the dynamic rise and fall of strain as the crack tip passed the gauges. Crack velocity can be determined from these strain gauge data but conducting strips were also used at the beginning and end of the crack path. Additionally, high-speed photography was used to monitor the crack progress and its velocity which was necessary when studying cracks that deviated from the path normal to the applied stress. The high-speed photographic studies were reported in Ref. 7. Interesting are the clean fracture surfaces obtained using the tongue method which are shown in Figure 2(c) which relate only to the inherent fracture characteristics of the material. Figure 2(d) also shows crack velocity versus stress relaxed load data for the polyethylene material together with data for polymethylmethacrylate and polycarbonate. From these, the threshold load to just propagate a crack can be obtained and the limiting crack velocity. Shown in Figure 3 are fracture surfaces that can be obtained for these three materials for different fracture conditions. The crack direction was from left to right. This is to study the ordered and random generation of fibril material. Important was that the whole length of the fracture surface of the tongue specimens had the same textural features which therefore could be specifically related to crack velocity and other fracture propagation parameters.

\section{DISCUSSION AND CONCLUSIONS}

Devising well validated experimental methods to provide fracture data that reveal the inherent properties of the material and the effect of different loading conditions is essential for the effective application of materials. It is convenient and helpful during early research and for monitoring manufacturing processes, if fracture data can be obtained from small specimens which relate well to those obtained from full-scale end product evaluation. The small specimen fracture methods presented in this paper meet these requirements and also can be used for studying material about a fracture in pressurised pipe or other product in service. The ability to obtain from fracturing small specimens crack surface features that occur in long rapid crack failure in pressurised pipes and other stressed products is very useful in the analysis of the reasons for the surface features. The tongue method is also proving to be valuable in the detailed study of the factors affecting the dynamic loading about a crack tip.

\section{ACKNOWLEDGEMENTS}

The author thanks the Science and Engineering Research Council and the Polymer Engineering Group for their support with this research which is part of a wider study.

\section{REFERENCES}

[1] Kalthoff, J. F., Int. J. Fract. 27 (1985) 277-298.

[2] Plati, E. and Williams, J. G. , Polym. Eng. Sci. 15 (1975) 470-477.

[3] Dear, J. P. and MacGillivray, J. H., J. Mat. Sci. 26 (1991) 2124-2132.

[4] Dear, J. P., J. Appl. Phys. 67(9) (1990) 4304-4312.

[5] Williams, J. G., Int. J. Fract. 33 (1987) 47-59.

[6] Dear, J.P., Clutton, E.Q. and Channell, A.D., Construction and Building Materials 7 (4) (1993) 207-211.

[7] Dear J. P., J. Mater. Sci. 26 (1991) 321-327. 